\title{
Using Fos Imaging in the Rat to Reveal the Anatomical Extent of the Disruptive Effects of Fornix Lesions
}

\author{
Seralynne D. Vann, ${ }^{1}$ Malcolm W. Brown, ${ }^{2}$ Jonathan T. Erichsen, ${ }^{3}$ and John P. Aggleton ${ }^{1}$ \\ ${ }^{1}$ School of Psychology, Cardiff University, Cardiff, CF10 3YG, United Kingdom, ${ }^{2}$ Department of Anatomy, University of \\ Bristol, Medical School, Bristol BS8 1TD, United Kingdom, and 'Department of Optometry and Vision Sciences, Cardiff \\ University, Cardiff CF10 3NB, United Kingdom
}

\begin{abstract}
Activity of the immediate early gene c-fos was compared across hemispheres in rats with unilateral fornix lesions. To engage Fos production, rats first performed a radial arm maze task that is severely disrupted by bilateral fornix lesions. Using immunohistochemical techniques, Fos-positive cells were visualized and counted in 39 sites in both hemispheres. Fornix lesions led to a significant reduction in Fos in all ipsilateral hippocampal subfields, as well as the entorhinal cortex and most of the subicular complex. Other sites that showed reduced activity included the ipsilateral retrosplenial, anterior cingulate, and postrhinal cortices. Subcortical regions showing significant Fos decreases included the anterior thalamic nuclei, supramammillary nucleus, diagonal band of Broca, and lateral septum. Thus, the effects of fornix lesions extended beyond the hippocampal formation and included sites not directly innervated by the tract. These changes were nevertheless selective, as shown by the lack of hemispheric
\end{abstract}

difference in any of the preselected control sites, the perirhinal cortex, or nucleus accumbens. Furthermore, there were no hemispheric differences in an additional group of animals with unilateral fornix lesions that were killed directly from the home cage. The location of Fos changes closely corresponded to those brain regions that when lesioned disrupt spatial working memory. Moreover, there was a correspondence between those brain regions that show increased Fos production in normal animals performing the radial arm maze task and those affected by fornix lesions. These results show that fornix transection has widespread, but selective, effects on a network of structures normally activated by spatial memory processes, with these effects extending beyond the hippocampal formation.

Key words: amnesia; fornix; hippocampus; immediate early genes; limbic cortices; rat; spatial memory; thalamus
The fornix is one of the principal fiber tracts in the brain and provides one of the major afferent and efferent systems for the hippocampus, connecting it with the diencephalon, striatum, basal forebrain, and prefrontal cortex. Consistent with its anatomical position, bilateral fornix lesions in animals often produce impairments similar to those seen after hippocampal lesions. These include severe deficits on tests of spatial working memory (Olton et al., 1979; Sutherland and Rodriguez, 1989; Aggleton et al., 1992; Ennaceur et al., 1996; Cassel et al., 1998). Interest in the role of the fornix has intensified after reports linking cases of anterograde amnesia in humans with damage to this tract (Heilman and Sypert, 1977; Gaffan and Gaffan, 1991; Hodges and Carpenter, 1991; D’Esposito et al., 1995; McMackin et al., 1995; Aggleton et al., 2000). In view of the evidence that the integrity of this fiber tract is important for normal memory, the present study sought to identify those brain regions that are adversely affected when the fornix is cut and, hence, might cause mnemonic deficits. This was achieved by using the expression of the immediate early gene c-fos, a marker of neuronal activation (Sagar et al., 1988; Dragunow and Faull, 1989; Herrera and Robertson, 1996).

Using immunohistochemical visualization of Fos, the product of c-fos, multiple brain sites can be simultaneously compared to identify regions likely to contribute to learning processes (Herdegen and Leah, 1998; Tischmeyer and Grimm, 1999). This technique has already been applied to normal rats engaged in spatial working memory tasks (Vann et al., 2000a,b). It was found that performance of the standard radial arm maze task leads to increased Fos in a network of sites including the hippocampus, subicular complex,

Received June 29, 2000; revised Aug. 8, 2000; accepted Aug. 9, 2000.

This research was supported by a programme grant from the Medical Research Council (35 42994). We thank Alison Baird, Jo Oswald, Clea Warburton, and Prof. Rodney Grahame for their assistance.

Correspondence should be addressed to Prof. J. P. Aggleton, School of Psychology, Cardiff University, Tower Building, Park Place, Cardiff CF10 3YG, UK. E-mail: Aggleton@cardiff.ac.uk.

Copyright (C) 2000 Society for Neuroscience $0270-6474 / 00 / 208144-09 \$ 15.00 / 0$ entorhinal cortex, postrhinal cortex, prelimbic cortex, retrosplenial cortex, and anterior thalamic nuclei (Vann et al., 2000a,b). A common feature of these regions is the links with the hippocampus, and many have connections via the fornix.

Having identified an array of sites that are activated in normal animals, we have now used a similar procedure to measure the effects of fornix lesions on performance of the standard radial arm maze task (Vann et al., 2000a,b). This task was chosen because rats with bilateral fornix lesions are consistently impaired (Olton et al., 1978, 1979; Neave et al., 1997; Cassel et al., 1998), but this also means that their abnormal sequence of arm choices could not be matched by a control group. To circumvent this problem, we have used animals with unilateral fornix lesions and compared levels of Fos production across hemispheres, thereby providing the closest behavioral control and eliminating problems of variation in Fos levels between animals.

\section{MATERIALS AND METHODS}

Subjects. Subjects were 10 male pigmented rats (DA strain; Harlan Olac, Bicester, UK) weighing from 210 to $250 \mathrm{gm}$ and $\sim 14$-weeks-old at the time of surgery. Ten days after surgery, animals were food-deprived to $85 \%$ of their free-feeding body weight and maintained at this level throughout the experiment. Water was available ad libitum. Animals were caged in pairs and before the study were thoroughly habituated to handling. All experiments were performed in accordance with the UK Animals (Scientific Procedures) Act (1986) and associated guidelines.

Apparatus. Testing was performed in an eight-arm radial maze. The maze consisted of an octagonal central platform (34-cm-diameter) and eight equally spaced radial arms $(87 \mathrm{~cm}$ long, $10 \mathrm{~cm}$ wide $)$. The base of the central platform and the arms were made of wood, whereas panels of clear Perspex (24 cm high) formed the walls of the arms. At the end of each arm was a food well $(2 \mathrm{~cm}$ in diameter and $0.5 \mathrm{~cm}$ deep). At the start of each arm was a clear Perspex guillotine door $(12 \mathrm{~cm}$ high) that controlled access in and out of the central platform. Each door was attached to a pulley system enabling the experimenter to control access to the arms. All animals were tested in the same rectangular room $(295 \times 295 \times 260 \mathrm{~cm})$ that contained salient visual cues such as geometric shapes and highcontrast stimuli on the walls.

Surgery. Animals were deeply anesthetized by intraperitoneal injection $(60 \mathrm{mg} / \mathrm{kg})$ of pentobarbitone sodium. Each animal was then placed in a 
stereotaxic headholder (David Kopf Instruments, Tujunga, CA), and the scalp was cut and retracted to expose the skull. The lesions were made by radiofrequency using a Radionics TCZ (Radionics, Burlington, VT) electrode $(0.3 \mathrm{~mm}$ tip length, $0.25 \mathrm{~mm}$ diameter $)$. This was lowered vertically into the fornix, and the tip temperature was raised to $75^{\circ} \mathrm{C}$ for $60 \mathrm{sec}$ using an RFG4-A Lesion Maker (Radionics, Burlington). Two lesions were made in only one hemisphere. The stereotaxic coordinates of the lesion relative to ear-bar zero were: anteroposterior (AP) +5.3 , dorsoventral (DV) +7.1, lateral $(\mathrm{L}) \pm 0.7$, and AP +5.3, DV + 7.0, and $\mathrm{L} \pm 1.7$. At the completion of all surgeries, the skin was sutured, an antibiotic powder (Acramide; Dales Pharmaceuticals, Skipton, UK) was applied, and animals received a $5 \mathrm{ml}$ injection of glucose saline and analgesia (Temgesic; Reckett and Colman). Approximately equal numbers of animals received lesions to the left or right hemisphere.

Behavioral training. Training began 2 weeks after surgery. Animals were trained to run in the maze using a standard working memory procedure (Olton et al., 1978). Thus, at the start of a trial all eight arms were baited with a single food pellet ( $45 \mathrm{mg}$; Noyes purified rodent diet). When the rat returned to the central platform, all doors were closed for $\sim 5 \mathrm{sec}$ before they were again opened, permitting the animal to make a choice. This continued until all eight arms had been visited. Retrieving all eight pellets constituted a single trial, composed of a minimum of eight arm runs. Training continued until the animals could reliably retrieve all eight pellets without making an error (i.e., not visit an arm that had already been entered on that trial). This typically required between seven and nine sessions. The only noteworthy aspect of the training was that each session consisted of multiple trials in the radial arm maze, one after the other, so that each session lasted for $30 \mathrm{~min}$ to prolong exposure to task demands. Therefore, after entering all eight arms the animals were removed from the maze while it was rebaited and then returned to the maze to perform a new trial. This was repeated for $30 \mathrm{~min}$. The delay between each trial (2 min) was the time it took to rebait all of the arms, and during this period the animals were placed in a traveling box which had an aluminum top, base, and sides $(10 \times 10 \times 26 \mathrm{~cm})$.

Final session: the final session was the same as those in training, i.e., 30 min of radial arm maze testing (approximately seven radial arm maze trials). After completion of testing each animal was placed in a soundproof box in a dark, quiet room for $90 \mathrm{~min}$. The animals had been habituated to this post-training procedure after all preceding sessions.

Home cage controls. Four additional male rats (DA strain; Harlan; 240-280 gm; 16-weeks-old) with unilateral fornix lesions were killed 3 weeks after surgery, directly from the home cage without previous behavioral testing. The surgical procedures and the postoperative recovery were identical to the animals in the main experimental group. Food and water were available ad libitum, and the animals were housed in pairs. The time of day of killing was the same for the experimental animals and the home cage controls. These animals provided controls to test whether fornix lesions alone alter baseline levels of Fos expression.

Immunocytochemistry. Ninety minutes after completing the final radial arm maze session (or at the same time of day for the controls), the animals were deeply anesthetized with pentobarbitone sodium $(1 \mathrm{mg} / \mathrm{kg})$ and perfused transcardially with $0.1 \mathrm{M}$ PBS followed by $4 \%$ paraformaldehyde in $0.1 \mathrm{M}$ PBS. The brains were removed and post-fixed in $4 \%$ paraformaldehyde for $4 \mathrm{hr}$ and then transferred to $30 \%$ sucrose overnight at $4^{\circ} \mathrm{C}$ Coronal sections were cut at $30 \mu \mathrm{m}$ on a freezing microtome, and a 1 in 2 series was collected in $0.1 \mathrm{~m}$ PBS containing $0.2 \%$ Triton X-100 (PBST). A peroxidase block was then performed where the sections were transferred to $0.3 \%$ hydrogen peroxide in PBST for $10 \mathrm{~min}$ to inhibit endogenous peroxidase and then washed several times with PBST. Sections were incubated in PBST containing Fos rabbit polyclonal antibody (1:5000; $\mathrm{Ab}-5$, Oncogene Science) for $48 \mathrm{hr}$ at $4^{\circ} \mathrm{C}$ with periodic rotation. Sections were then washed with PBST and incubated in biotinylated goat anti-rabbit secondary antibody (diluted 1:200 in PBST; Vectastain, Vector Laboratories, Burlingame, CA) and 1.5\% normal goat serum for $2 \mathrm{hr}$ at room temperature on a rotator. Sections were then washed and processed with avidin-biotinylated horseradish peroxidase complex in PBST (Elite kit Vector Laboratories) for $1 \mathrm{hr}$ at room temperature, again with constant rotation. Sections were washed again in PBST and then in $0.05 \mathrm{M}$ Tris buffer. The reaction was then visualized using diaminobenzidine (DAB Substrate kit; Vector Laboratories). The reaction was stopped by washing in cold PBS, and then sections were mounted on gelatin-coated slides, dehydrated through a graded series of alcohols, and coverslipped. A separate one in four series of sections was mounted directly onto slides and stained using cresyl violet, a Nissl stain, for histological identification of specific brain regions.

Image analysis. Sections were scanned using a Leitz Diaplan microscope equipped with a Dage MTI CCD72S camera interfaced to a Power Macintosh computer (8500/150) by a Scion LG-3 frame grabber board. After image processing, counts of the stained nuclei were performed using the public domain NIH Image program. Cortical areas were assessed using counts of nuclei labeled above threshold. The threshold was set at the same level for both hemispheres of each section sampled. Counts were made in a standard frame sample area $(0.78 \times 0.55 \mathrm{~mm})$ using a $10 \times$ objective, and the camera was positioned so that the counts were taken across all cortical layers. For dorsal and ventral hippocampal counts, hippocampal subfield (dentate gyrus, CA3 and CA1) counts, and some of the smaller thalamic nuclei, the entire extent of the target region within the selected coronal sections was assessed (Fig. 1). For all brain areas analyzed, counts were taken from at least four consecutive sections from each hemisphere, and these counts were averaged to produce a mean. The counts were then normalized across the two hemispheres by dividing the scores from one hemisphere by the sum from both hemispheres and the result expressed as a percentage. Thus, all pairs of normalized scores sum to 100. These normalized data were then used for the statistical analyses, unless otherwise stated. The separate groups of regions were analyzed in overall ANOVA with two factors: hemisphere and brain region. When appropriate, the simple effects for each brain region were analyzed as recommended by Winer (1971).

The NIH Image Program was also used to quantify the size of the fornix lesion. The entire fornix was outlined on the control side and the extent of that portion of the fornix remaining on the lesioned side was traced. After allowing for the appropriate scale and pixel aspect ratio factors at a total magnification of 25 on the microscope (to allow measurements in square micrometers), the areas of the fornix in both hemispheres were measured and compared.

Regions of interest. Cytoarchitectonic subfields were identified from coronal sections, using the nomenclature of Swanson (1992). Diagrams showing regions sampled are shown in Figure 1. All of the sites from which it was decided a priori to count Fos-positive cells are presented. None is excluded on the basis of subsequent Fos counts.

Counts were taken from a number of "control" cortical and subcortical regions for purposes of comparison in order to determine the specificity of any findings. Counts were taken across all layers of cortical regions. These regions were selected on the criteria that they were not connected with the fornix and were not known to have a specific role in spatial memory. The cortical areas were the visual cortex [primary visual area (VISp)], the somatosensory cortex [primary somatosensory area (SSp)], and the motor cortex [primary motor area (MOp)]. The subcortical areas were the medial geniculate nucleus (MG), the periaqueductal gray (PAG), and the pontine gray $(\mathrm{PG})$.

Cytoarchitectonic subfields within the hippocampal formation consisted of the dentate gyrus (DG), CA3, and CA1 (Fig. 1). The "dorsal" and "ventral" hippocampal counts were taken from the same coronal slices and corresponded to AP level $-5.0 \mathrm{~mm}$ relative to bregma in Swanson (1992). The border between these two regions (Fig. 1) corresponded to DV level $-5.0 \mathrm{~mm}$ from bregma (Moser et al., 1995). The dorsal and ventral hippocampal counts involved just the DG and fields CA1 and CA3, i.e., not the subiculum complex. At this level the dentate gyrus is present in both the dorsal and ventral hippocampus. Counts were also taken from the dorsal, ventral, and caudal subiculum, and the presubiculum, parasubiculum, and postsubiculum. As previous studies have shown that fornix damage does not produce retrograde cell death in the hippocampus (Daitz and Powell, 1954), the counts were compared directly.

We counted Fos-reactive cells in limbic cortices, including the parahippocampal region (Witter et al., 1989; Burwell et al., 1995). The perirhinal counts involved both areas 35 and 36 (Burwell et al., 1995), whereas the postrhinal cortex only involved cortex posterior to the perirhinal cortex and dorsal to the rhinal sulcus (Burwell and Amaral, 1998; corresponding to the ectorhinal area in Swanson, 1992). The lateral and medial entorhinal cortices were considered separately in light of their different connection patterns (Witter et al., 1989; Naber et al., 1997). Counts were also taken from the prelimbic area, rostral and caudal levels of the anterior cingulate cortex, rostral and caudal levels of the retrosplenial cortex, and the parietal cortex (Fig. 1).

Finally, a number of subcortical sites were examined. These included various thalamic nuclei implicated in mnemonic processes such as the anterodorsal, anteroventral, anteromedial, laterodorsal, and mediodorsal thalamic nuclei. Counts were also made in nucleus reuniens, the rostral reticular nucleus, lateral and medial septum, diagonal band of Broca, nucleus accumbens, and supramammillary nuclei. Evidence that fornix lesions can lead to cell loss in the medial septum (Gage et al., 1986) means that Fos counts in this region might underestimate activity. Finally, previous studies had revealed that neither the medial or lateral mammillary bodies express c-fos, and so they were not included (Vann et al., 2000a).

\section{RESULTS}

\section{Fornix lesions}

The extent of the 10 unilateral fornix lesions is shown in Figure 2, and a photomicrograph of a typical lesion is shown in Figure 3. The lesions included both the fornix and the fimbria. None of the lesions encroached on the intact hemisphere, and there was no damage to any of the CA fields or the dentate gyrus. All lesions spared the cingulum bundle, although in one animal there was slight damage to the corpus callosum and in another the lesion extended into the very caudal part of the lateral septum. The ventral hippocampal commissure was lesioned in all cases, although 


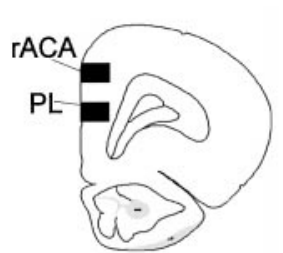

$+3.60$
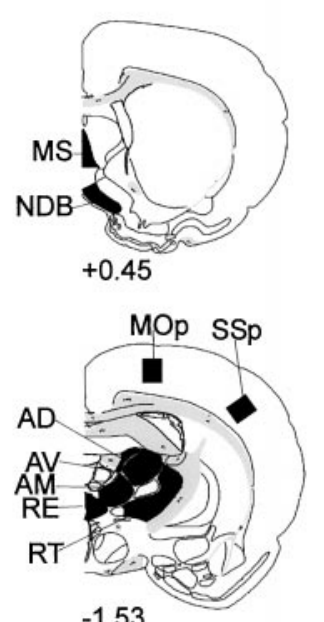

$-1.53$
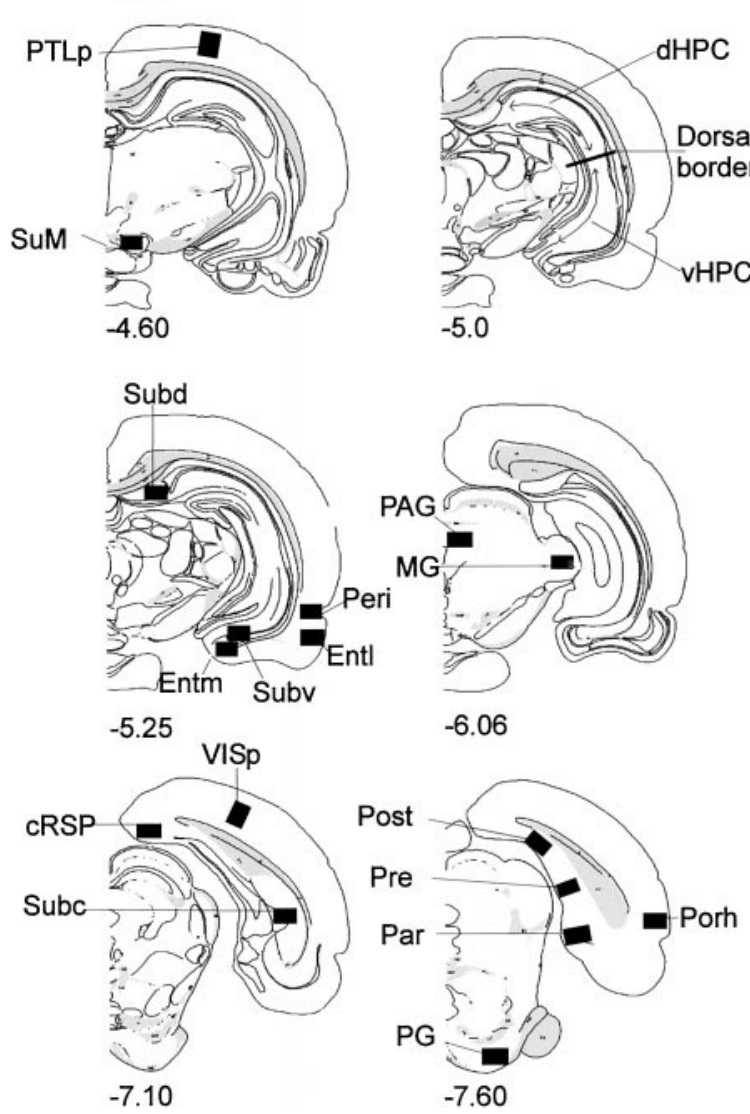

Figure 1. Diagrams of coronal sections indicating areas sampled. The numbers indicate the distance (in millimeters) of the sections from bregma (Swanson, 1992). See Table 1 for list of abbreviations.

the dorsal hippocampal commissure remained intact. The lesions were complete in 8 of 10 cases, the only sparing occurring in the most medial part of the fornix in the two cases. The percentage of the fimbria/fornix that was removed ranged from 79 to $100 \%$ (mean, 93\%). Even though both the fimbria and fornix are included
Table 1. Abbreviations of brain regions used in figures and tables

\begin{tabular}{|c|c|}
\hline Abbreviation & Brain region \\
\hline \multicolumn{2}{|c|}{ Control regions } \\
\hline MOp & Primary motor area \\
\hline $\mathrm{SSp}$ & Primary somatosensory area \\
\hline VISp & Primary visual area \\
\hline MG & Medial geniculate nucleus \\
\hline PG & Pontine gray \\
\hline PAG & Periaqueductal gray \\
\hline \multicolumn{2}{|l|}{ Hippocampus } \\
\hline $\mathrm{dHPC}$ & Dorsal hippocampus \\
\hline vHPC & Ventral hipposcampus \\
\hline DG & Dentate gyrus \\
\hline CA3 & CA3 \\
\hline CA1 & CA1 \\
\hline \multicolumn{2}{|c|}{ Subicular cortices } \\
\hline Subd & Dorsal subiculum \\
\hline Subv & Ventral subiculum \\
\hline Subc & Caudal subiculum \\
\hline Post & Postsubiculum \\
\hline Pre & Presubiculum \\
\hline Par & Parasubiculum \\
\hline \multicolumn{2}{|c|}{ Limbic cortices } \\
\hline PL & Prelimbic cortex \\
\hline rACA & Rostral anterior cingulate cortex \\
\hline cACA & Caudal anterior cingulate cortex \\
\hline rRSP & Rostral retrosplenial cortex \\
\hline cRSP & Caudal retrosplenial cortex \\
\hline PTLp & Parietal cortex \\
\hline ENTl & Lateral entorhinal cortex \\
\hline ENTm & Medial entorhinal cortex \\
\hline Porh & Postrhinal cortex \\
\hline Peri & Perirhinal cortex \\
\hline \multicolumn{2}{|c|}{ Thalamic nuclei } \\
\hline $\mathrm{AD}$ & Anterodorsal thalamic nucleus \\
\hline $\mathrm{AV}$ & Anteroventral thalamic nucleus \\
\hline $\mathrm{AM}$ & Anteromedial thalamic nucleus \\
\hline MD & Mediodorsal thalamic nucleus \\
\hline $\mathrm{LD}$ & Laterodorsal thalamic nucleus \\
\hline RE & Nucleus reuniens \\
\hline RT & Reticular thalamic nucleus \\
\hline \multicolumn{2}{|c|}{ Subcortical regions } \\
\hline SuM & Supramammillary nucleus \\
\hline LS & Lateral septum \\
\hline MS & Medial septum \\
\hline $\mathrm{ACB}$ & Nucleus accumbens \\
\hline NDB & Nucleus of diagonal band of broca \\
\hline
\end{tabular}

in the lesions, the surgeries are referred to as unilateral "fornix" lesions.

\section{Behavioral results}

On the final test day, the animals performed the standard version of the eight-arm radial maze. Testing took place over a $30 \mathrm{~min}$ session, and animals typically ran a total of seven trials (each trial comprises the retrieval of all eight pellets) in this session. The mean number of errors per trial across all trials within this session ( \pm SEM values in parentheses) was $0.9(0.1)$. The mean number of correct responses in the first eight choices, across all trials in the final session, was $7.3(0.1)$. These performance levels are comparable to those of normal rats that were trained and tested in exactly the same way (Vann et al., 2000a,b) 


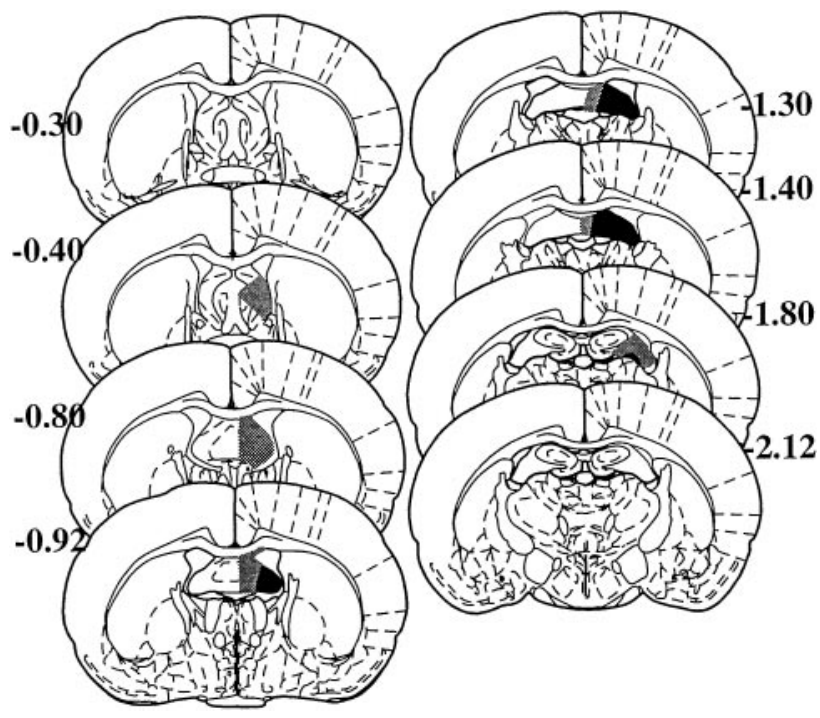

Figure 2. Coronal sections illustrating the extent of the largest (gray) and smallest (black) fornix lesions. The numbers indicate the distance (in millimeters) of the sections from bregma (Paxinos and Watson, 1997).

\section{Fos counts}

\section{Home cage control animals}

Counts were taken from the intact and fornix-lesioned hemispheres in 39 brain sites in animals that had been killed directly from the home cage without previously performing the radial arm maze task. There were no significant differences between the two hemispheres in any of the areas examined, as demonstrated by a lack of effect of condition in the hippocampal formation $(F<1)$, subicular complex $(F<1)$, limbic cortices $(F<1)$, thalamic nuclei $(F<1)$, subcortical regions $(F<1)$, and the six control regions $(F<1)$. It should be noted that the raw counts for these animals were often very low (Table 2), consistent with the fact that they reflect basal levels (Curran, 1988; Hughes et al., 1992).

\section{Spatial working memory animals}

Because there were no differential effects of lesion in the right or left fornix on Fos counts in any of the regions (all $F<1$ ), the side of the fornix lesion is not considered further.

Control regions. The cortical and subcortical control regions examined were the MOp, SSp, VISp, MG, PG, and PAG (Fig. 1). There was no difference in Fos counts across the two hemispheres, as shown by a lack of effect of hemisphere $\left(F_{(1,18)}=1.1 ; p>0.1\right)$, and subsequent analyses showed that this pattern was the same across all regions examined $\left(\mathrm{MG}, F_{(1,107)}=3.3, p>0.05\right.$; all other control regions, $F<1$ ) (Fig. 4 ).

Hippocampus. The dorsal and ventral counts were taken from the same coronal sections and consisted of the dentate gyrus, CA3, and CA1. The separate subfields were counted near the septal pole of the hippocampus where only the dorsal hippocampus is present. There were much higher levels of Fos counts in the intact hemisphere, as compared to the lesioned hemisphere, which was shown by a main effect of condition for the hippocampus $\left(F_{(1,18)}=46.2\right.$; $p<0.0001)$. Subsequent analyses revealed that this difference was significant for every region examined (dorsal hippocampus, $F_{(1,87)}=4.1, p<0.05$; ventral hippocampus, $F_{(1,87)}=11.0, p<$ 0.001 ; dentate gyrus, $F_{(1,87)}=28.4, p<0.001$; CA3, $F_{(1,87)}=16.4$, $p<0.001$; CA1, $\left.F_{(1,87)}=8.6, p<0.001\right)$ (Fig. 4).

Subicular cortices. This group of structures includes the dorsal subiculum, ventral subiculum, caudal subiculum, postsubiculum, presubiculum, and parasubiculum (Fig. 1). Performing the radial arm maze task resulted in increased numbers of Fos-positive nuclei in the intact hemisphere compared to the lesioned hemisphere. This was shown by a main effect of condition $\left(F_{(1,18)}=179.0 ; p<\right.$ $0.0001)$. Further analyses also showed significant differences in the

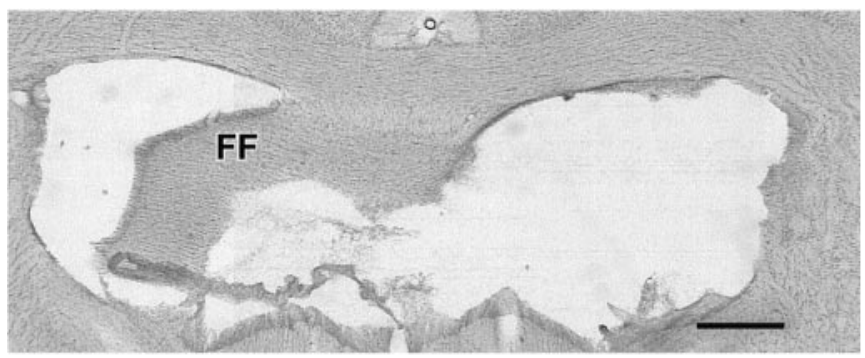

Figure 3. Photomicrograph of a Nissl-stained coronal section showing a unilateral fornix lesion. The lesion in the right hemisphere is $\sim 96 \%$ complete. FF, Fimbria/fornix. Scale bar, $500 \mu \mathrm{m}$.

ventral subiculum, postsubiculum, presubiculum, and parasubiculum (ventral subiculum, $F_{(1,102)}=53.3, p<0.001$; postsubiculum, $F_{(1,102)}=22.6, p<0.001$; presubiculum, $F_{(1,102)}=22.3, p<0.001$; parasubiculum, $\left.F_{(1,102)}=20.6, p<0.001\right)$ but not in the dorsal subiculum $\left(F_{(1,102)}=0.6, p>0.1\right)$ or caudal subiculum $\left(F_{(1,102)}=\right.$ $1.1, p>0.1$ ) (Fig. 4).

Limbic cortices. Counts were made in prelimbic cortex, rostral and caudal levels of the anterior cingulate area, rostral and caudal levels of the retrosplenial cortex, the parietal cortex, medial and lateral entorhinal cortex, postrhinal cortex, and perirhinal cortex (Fig. 1). Performing the radial arm maze task resulted in higher numbers of Fos-positive neurons in the intact hemisphere, as shown by a main effect of hemisphere $\left(F_{(1,18)}=90.1 ; p<0.0001\right)$ as well as a group-region interaction $\left(F_{(9,162)}=12.2 ; p<0.0001\right)$. Subsequent analyses revealed that this hemispheric difference was significant for each region examined except for the perirhinal cortex and the parietal cortex (prelimbic cortex, $F_{(1,180)}=12.7, p<$ 0.001 ; rostral anterior cingulate area, $F_{(1,180)}=7.6, p<0.01$; caudal anterior cingulate area, $F_{(1,180)}=20.4, p<0.001$; rostral retrosplenial cortex, $F_{(1,180)}=17.2, p<0.001$; caudal retrosplenial cortex, $F_{(1,180)}=24.1, p<0.001$; parietal cortex, $F<1$; medial entorhinal cortex, $F_{(1,180)}=79.1, p<0.001$; lateral entorhinal cortex, $F_{(1,180)}=20.3, p<0.001$; postrhinal cortex, $F_{(1,180)}=7.1$, $p<0.01$; perirhinal cortex, $F<1$ ) (Fig. 5). All regions reaching significance showed higher Fos counts in the intact hemisphere, except the prelimbic cortex where the lesioned hemisphere showed higher c-fos expression.

Thalamic nuclei. For the seven thalamic nuclei examined there was a main effect of hemisphere $\left(F_{(1,18)}=35.7 ; p<0.0001\right)$. Subsequent analyses showed that the difference between the lesioned and intact hemispheres was significant for all three anterior thalamic nuclei (anterodorsal, $F_{(1,126)}=15.6, p<0.001$; anteroventral, $F_{(1,126)}=17.0, p<0.001$; anteromedial, $F_{(1,126)}=29.9, p<$ $0.001)$. In all of these nuclei, there were more Fos-positive cells in the intact hemisphere. The remaining thalamic nuclei did not show a significant difference (mediodorsal, $F<1$; laterodorsal, $F<1$; reuniens, $F_{(1,126)}=2.3, p>0.1$; reticular, $\left.F_{(1,126)}=3.2, p>0.05\right)$ (Fig. 6).

Subcortical regions. These comprised the lateral septum, the medial septum, the supramammillary nuclei, the diagonal band of Broca, and nucleus accumbens (Fig. 1). There was a significant main effect of hemisphere for these regions $\left(F_{(1,18)}=14.9 ; p=\right.$ $0.0011)$. Subsequent analyses showed that this difference was only significant for the supramammillary nuclei, the lateral septum, and the diagonal band of Broca (supramammillary nuclei, $F_{(1,90)}=5.8$, $p<0.05$; lateral septum, $F_{(1,90)}=9.7, p<0.01$; medial septum, $F<1$; nucleus accumbens, $F<1$; diagonal band of Broca, $F_{(1,90)}=$ 8.8, $p<0.01$ ) (Fig. 6).

\section{Raw counts of nuclei}

To show the actual numbers of stained nuclei observed in each brain region examined, the means and SEM values for raw scores are presented in Table 2, and examples of staining levels are shown in Figure 7. ANOVAs performed using the raw scores of nuclei 
Table 2. Raw counts of nuclei

\begin{tabular}{|c|c|c|c|c|c|}
\hline Region & $\begin{array}{l}\text { RAM-Intact } \\
n=10\end{array}$ & $\begin{array}{l}\text { RAM-Lesion } \\
n=10\end{array}$ & $\begin{array}{l}\text { Significance } \\
\text { of difference }\end{array}$ & $\begin{array}{l}\text { Home cage- } \\
\text { intact } \\
n=4\end{array}$ & $\begin{array}{l}\text { Home } \\
\text { cage-lesion } \\
n=4\end{array}$ \\
\hline \multicolumn{6}{|c|}{ Control regions } \\
\hline MOp & $70.4 \pm 10.8$ & $69.5 \pm 10.7$ & - & $3.2 \pm 1.4$ & $2.7 \pm 1.1$ \\
\hline $\mathrm{SSp}$ & $62.1 \pm 12.4$ & $61.8 \pm 11.9$ & - & $1.5 \pm 0.3$ & $1.5 \pm 0.4$ \\
\hline VISp & $99.1 \pm 12.9$ & $97.2 \pm 11.9$ & - & $11.3 \pm 0.8$ & $9.8 \pm 1.5$ \\
\hline MG & $1.3 \pm 0.2$ & $1.4 \pm 0.2$ & - & $0.6 \pm 0.6$ & $0.4 \pm 0.2$ \\
\hline PG & $69.7 \pm 13.8$ & $69.7 \pm 13.4$ & - & $15.6 \pm 3.0$ & $17.0 \pm 3.4$ \\
\hline PAG & $31.5 \pm 4.0$ & $31.3 \pm 3.7$ & - & $10.5 \pm 2.5$ & $10.6 \pm 3.7$ \\
\hline \multicolumn{6}{|c|}{ Hippocampus } \\
\hline dHPC & $18.8 \pm 3.2$ & $14.0 \pm 2.6$ & $* *$ & $2.5 \pm 0.8$ & $3.5 \pm 0.8$ \\
\hline vHPC & $52.3 \pm 7.7$ & $33.2 \pm 4.5$ & $*$ & $6.1 \pm 1.6$ & $5.6 \pm 1.4$ \\
\hline DG & $7.7 \pm 1.1$ & $3.9 \pm 1.0$ & $* * *$ & $0.5 \pm 0.1$ & $0.5 \pm 0.1$ \\
\hline CA3 & $3.3 \pm 0.5$ & $2.8 \pm 0.8$ & - & $0.1 \pm 0.1$ & $0.1 \pm 0.1$ \\
\hline CA1 & $3.7 \pm 0.7$ & $2.6 \pm 0.5$ & - & $0.1 \pm 0.1$ & $0.1 \pm 0.1$ \\
\hline \multicolumn{6}{|c|}{ Subicular cortices } \\
\hline Subd & $9.8 \pm 2.5$ & $9.3 \pm 2.2$ & - & $0.0 \pm 0.0$ & $0.0 \pm 0.0$ \\
\hline Subv & $36.5 \pm 3.5$ & $19.2 \pm 2.8$ & $* * *$ & $1.9 \pm 0.4$ & $1.6 \pm 0.1$ \\
\hline Subc & $33.1 \pm 6.4$ & $30.8 \pm 5.6$ & - & $0.5 \pm 0.2$ & $0.5 \pm 0.2$ \\
\hline Post & $118.6 \pm 20.1$ & $83.1 \pm 19.5$ & $* * *$ & $17.7 \pm 3.7$ & $17.7 \pm 3.8$ \\
\hline Pre & $52.3 \pm 11.0$ & $36.0 \pm 8.8$ & $* *$ & $5.6 \pm 2.5$ & $5.7 \pm 1.9$ \\
\hline Par & $29.8 \pm 5.5$ & $20.7 \pm 4.1$ & $* *$ & $3.4 \pm 1.9$ & $3.1 \pm 1.6$ \\
\hline \multicolumn{6}{|c|}{ Limbic cortices } \\
\hline PL & $70.4 \pm 7.8$ & $92.7 \pm 11.7$ & $*$ & $2.5 \pm 1.1$ & $3.0 \pm 1.3$ \\
\hline rACA & $39.6 \pm 8.2$ & $37.0 \pm 10.1$ & - & $0.7 \pm 0.3$ & $0.8 \pm 0.1$ \\
\hline cACA & $74.4 \pm 12.7$ & $55.1 \pm 10.8$ & $*$ & $0.6 \pm 0.3$ & $0.6 \pm 0.3$ \\
\hline rRSP & $206.8 \pm 18.0$ & $160.2 \pm 18.7$ & $* * *$ & $4.1 \pm 1.9$ & $3.9 \pm 1.9$ \\
\hline cRSP & $117.8 \pm 16.1$ & $84.7 \pm 11.4$ & $* *$ & $2.4 \pm 1.0$ & $2.1 \pm 1.1$ \\
\hline PTLp & $64.3 \pm 9.3$ & $63.1 \pm 7.9$ & - & $3.8 \pm 1.2$ & $3.7 \pm 1.3$ \\
\hline ENTl & $26.1 \pm 4.1$ & $19.8 \pm 3.5$ & $*$ & $3.6 \pm 0.7$ & $3.6 \pm 0.9$ \\
\hline ENTm & $60.7 \pm 7.9$ & $35.3 \pm 5.7$ & $* *$ & $2.6 \pm 1.1$ & $3.2 \pm 1.9$ \\
\hline Porh & $26.5 \pm 4.9$ & $21.5 \pm 3.8$ & $*$ & $3.4 \pm 0.8$ & $3.8 \pm 1.2$ \\
\hline Peri & $34.0 \pm 4.2$ & $35.5 \pm 3.9$ & - & $3.8 \pm 1.8$ & $3.5 \pm 1.5$ \\
\hline \multicolumn{6}{|c|}{ Thalamic nuclei } \\
\hline $\mathrm{AD}$ & $3.8 \pm 1.5$ & $1.5 \pm 0.4$ & - & $0.1 \pm 0.1$ & $0.3 \pm 0.3$ \\
\hline $\mathrm{AV}$ & $7.4 \pm 1.8$ & $5.5 \pm 1.6$ & $* *$ & $0.3 \pm 0.3$ & $0.2 \pm 0.2$ \\
\hline $\mathrm{AM}$ & $24.4 \pm 7.1$ & $10.3 \pm 3.1$ & $*$ & $0.0 \pm 0.0$ & $0.0 \pm 0.0$ \\
\hline MD & $11.8 \pm 3.9$ & $11.4 \pm 3.8$ & - & $0.3 \pm 0.3$ & $0.3 \pm 0.3$ \\
\hline $\mathrm{LD}$ & $3.7 \pm 1.1$ & $3.9 \pm 1.3$ & - & $0.1 \pm 0.1$ & $0.2 \pm 0.2$ \\
\hline $\mathrm{RE}$ & $17.1 \pm 3.1$ & $13.7 \pm 2.0$ & - & $3.3 \pm 1.1$ & $3.1 \pm 1.1$ \\
\hline RT & $5.2 \pm 0.8$ & $4.1 \pm 0.6$ & - & $1.0 \pm 1.0$ & $0.8 \pm 0.8$ \\
\hline \multicolumn{6}{|c|}{ Subcortical regions } \\
\hline SuM & $37.7 \pm 11.4$ & $33.6 \pm 10.1$ & - & $6.7 \pm 3.8$ & $6.8 \pm 3.9$ \\
\hline LS & $48.9 \pm 6.3$ & $41.5 \pm 6.0$ & $*$ & $1.3 \pm 0.5$ & $1.5 \pm 0.7$ \\
\hline MS & $34.3 \pm 5.2$ & $32.0 \pm 4.6$ & - & $7.1 \pm 5.9$ & $7.9 \pm 6.4$ \\
\hline $\mathrm{ACB}$ & $37.7 \pm 7.2$ & $37.2 \pm 6.1$ & - & $1.8 \pm 0.4$ & $2.2 \pm 0.8$ \\
\hline NDB & $4.0 \pm 1.1$ & $3.4 \pm 1.0$ & - & $1.4 \pm 0.8$ & $1.5 \pm 1.0$ \\
\hline
\end{tabular}

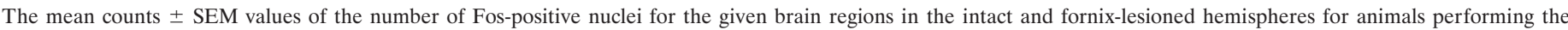

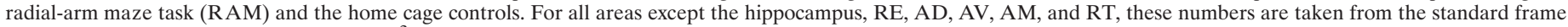

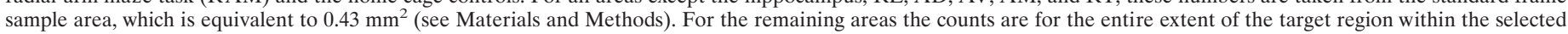
coronal sections. Significance of differences in counts of nuclei: ${ }^{*} p<0.05,{ }^{*} p<0.01, * * p<0.001$.

resulted in a very similar pattern of results to those found using the normalized scores. Thus, of the 45 analyses reported in the previous section only six differ. In each case, a region that was previously shown to have a significant difference across the two hemispheres no longer reached the 0.05 level of significance (rostral anterior cingulate cortex, anterodorsal thalamic nuclei, CA3, CA1, supramammillary nuclei, diagonal band of Broca). Thus, a total of 17 regions show significant differences between the two hemispheres irrespective of the scores used.

\section{DISCUSSION}

Using Fos as a marker, we compared levels of neuronal activation across hemispheres in animals with unilateral fornix lesions performing a test of spatial working memory. In normal rats, a number of interlinked brain sites that have fornix connections show increased c-fos activation during performance of the same test (Vann et al., 2000a,b), suggesting a network of regions that support this class of task. Furthermore, bilateral fornix lesions consistently 

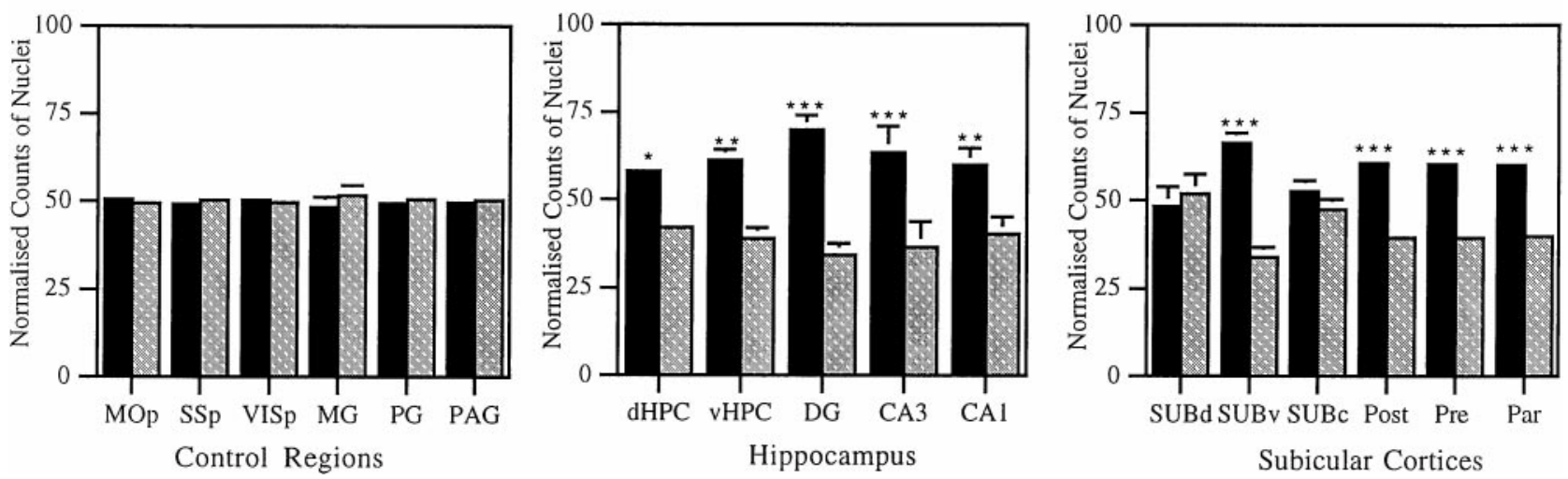

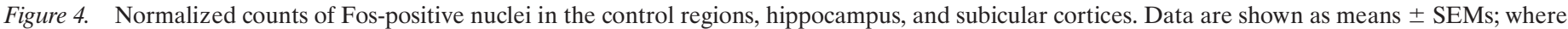

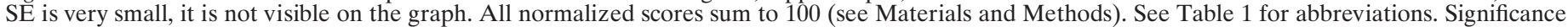
of hemispheric differences in normalized counts: ${ }^{*} p<0.05,{ }^{*} p<0.01,{ }^{*} * *<<0.001$.

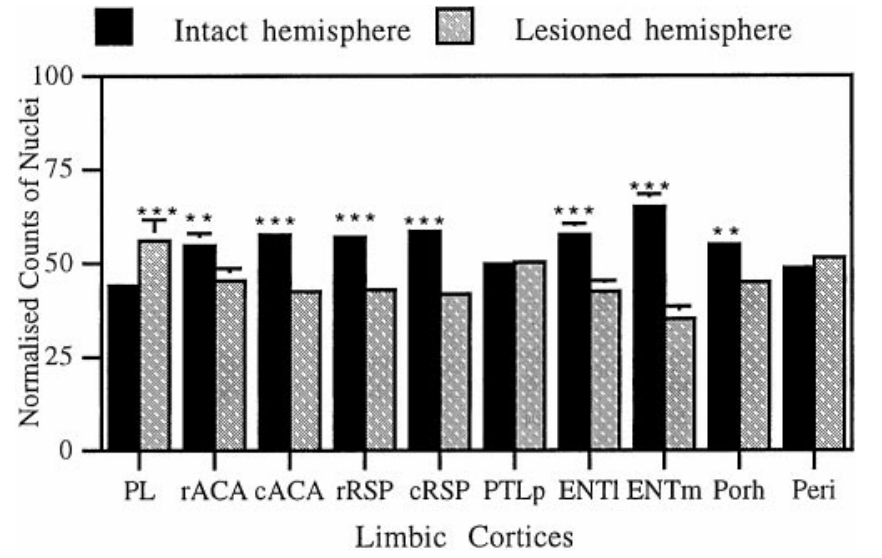

Figure 5. Normalized counts of Fos-positive nuclei in the limbic cortices. Data are shown as means $\pm \mathrm{SE}$; where SE is very small, it is not visible on the graph. All normalized data sum to 100 (see Materials and Methods). See Table 1 for abbreviations. Significance of hemispheric differences in normalized counts: $* p<0.05, * * p<0.01$, *** $p<0.001$.

impair performance of the same task (Olton et al., 1979; Aggleton et al., 1992; Cassel et al., 1998). Thus, this study sought to identify those regions altered by fornix lesions and to compare them with regions thought to be normally involved in this task. Although the unilateral lesions were complete and involved the ventral hippocampal commissure, they had no overt effect on performance levels. A possible limitation arises from crossed projections leaving the fornix. One consequence is that the control "intact" hemisphere may not be completely normal because it will have lost connections via the contralateral fornix. Similarly, the "disconnected" hemisphere may still receive some inputs from the contralateral hemisphere via other routes. Axonal sprouting has also been shown to occur in animals with fornix lesions (Cassel et al., 1997), and this may influence hippocampal activity. All of these effects are, however, most likely to attenuate hemispheric differences and are therefore of principal concern when no difference is observed between the hemispheres.

The principal region of interest was the hippocampus because there are many similarities between the behavioral effects of fornix and hippocampal lesions (Olton et al., 1979; Sutherland and Rodriguez, 1989; Aggleton et al., 1992; Cassel et al., 1998). Decreased Fos levels were found in all three hippocampal subfields (dentate gyrus, CA3, and CA1) and in both the dorsal and ventral parts of the hippocampus, as well as the ventral subiculum, presubiculum, and parasubiculum. The lack of a significant difference in the dorsal subiculum may reflect the sparing of interhemispheric inputs from the entorhinal cortex via the dorsal hippocampal commissure (Steward, 1976; Wyss et al., 1980).

These widespread hippocampal changes presumably reflect the loss of fornical projections from the medial septum, diagonal band of Broca, locus coeruleus, and raphe nuclei (Daitz and Powell, 1954; Swanson and Cowan, 1979; Amaral and Kurz, 1985; Cassel et al., 1997). These disconnections are not, however, complete because $\sim 45 \%$ of the cholinergic input from the septal region, $90 \%$ of the noradrenergic input from locus coeruleus, and $70 \%$ of the serotonergic input from the raphe nuclei to the hippocampus is via nonfornical routes in the rat (Amaral and Kurz, 1985; Amaral and Witter, 1995; Cassel et al., 1997). Nevertheless, widespread relative hypoactivity was found, in marked contrast with the baseline control animals that showed no interhemispheric differences in any of the sites measured, including the hippocampus. The counts in the lesioned hemisphere of animals performing the spatial working memory task were still consistently higher than those of the home cage animals (Table 2). This shows that regions such as the hippocampus are still being activated above normal resting levels and may help to explain why fornix lesions do not mimic the full effects of hippocampectomy (Whishaw and Jarrard, 1995; Warburton et al., 1998).

The present findings support and extend a study examining the effects of fornix lesions on hippocampal cAMP response elementbinding protein (CREB), which is important for c-fos transcription (Morgan and Curran, 1991). Bilateral fornix lesioned rats were trained on an inhibitory avoidance task and showed both behavioral deficits and reduced hippocampal CREB after training (Taubenfeld et al., 1999). Thus, fornix lesions decrease hippocampal protein production in biochemical pathways associated with plastic processes after the performance of two very different learning tasks, inhibitory avoidance and spatial working memory. The two studies point to a similar underlying deficit after fornix transection because the Fos changes in the present study might be secondary to CREB reduction.

In the present study, widespread changes were also found in limbic cortices with significant Fos reduction in the entorhinal, retrosplenial, and cingulate cortices. The prelimbic cortex proved to be an exception. Although it is innervated by fornical projections from both CA1 and the ventral subiculum (Meibach and Siegel, 1977a; Swanson, 1981; Jay et al., 1989; Canteras and Swanson, 1992), significantly greater Fos levels were present in the lesioned hemisphere. The cause of this is unclear because the direct hippocampal inputs to the prelimbic cortex are thought to be glutamatergic and, hence, excitatory (Jay et al., 1996).

Of those examined, the only thalamic nuclei to show significant Fos differences were the anterior thalamic nuclei. Consistent with this, the anterior thalamic nuclei receive dense fornical inputs from the subicular complex, as well as a further direct component via the 
Figure 6. Normalized counts of Fos-positive nuclei in the thalamic nuclei and subcortical regions. Data are shown as means $\pm \mathrm{SE}$; where $\mathrm{SE}$ is very small, it is not visible on the graph. All normalized data sum to 100 (see Materials and Methods). See Table 1 for abbreviations. Significance of hemispheric differences in normalized counts: ${ }^{*} p<0.05,{ }^{* *} p<0.01$, $* * * p<0.001$.

Intact hemisphere

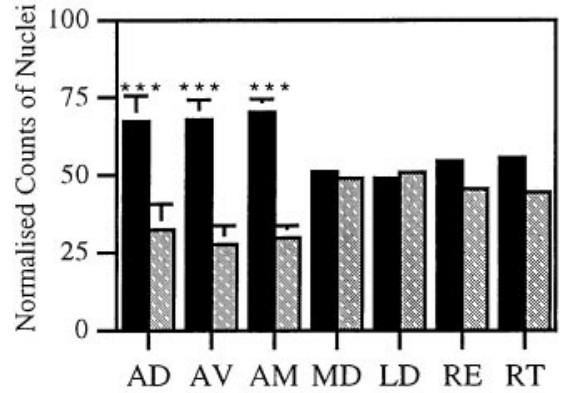

Thalamic Nuclei

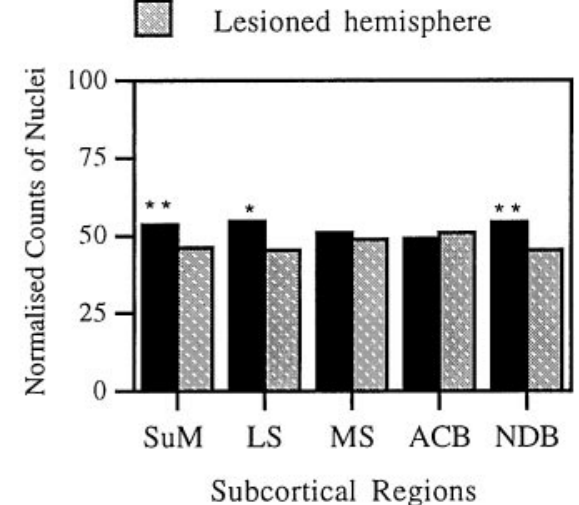

Subcortical Regions
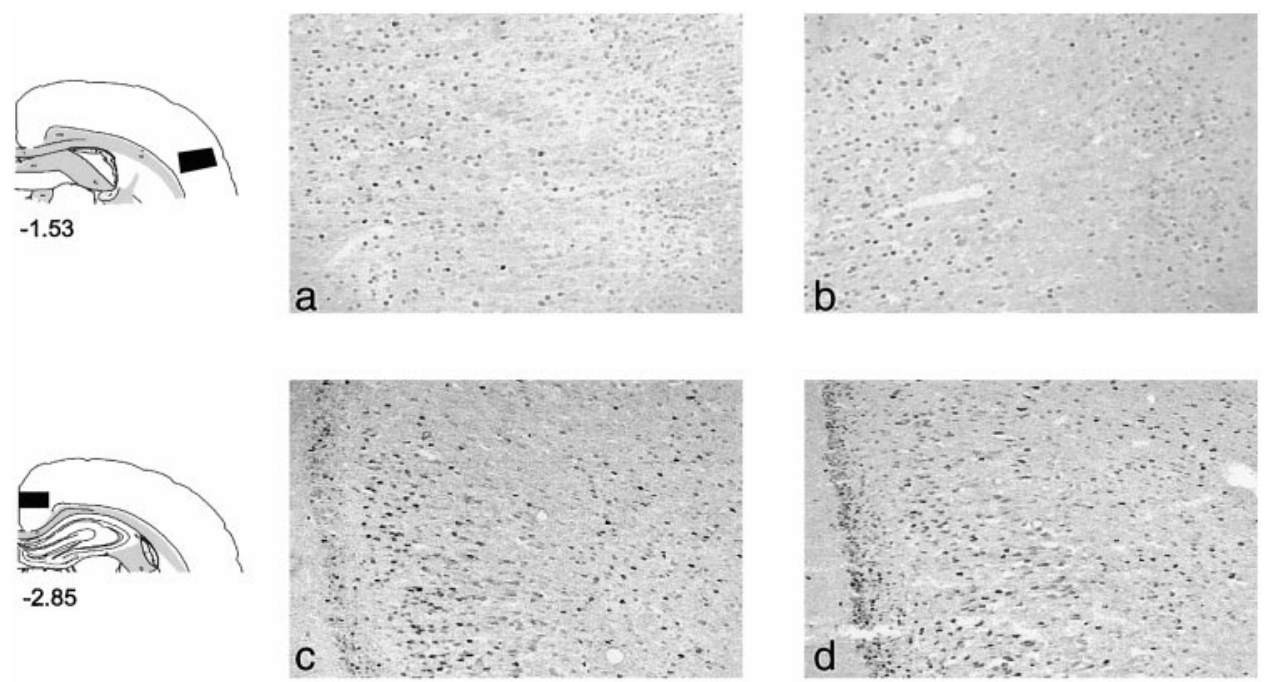

Figure 7. Photomicrographs showing Fospositive nuclei in the lesioned (left column; $a$, $c, e$ ) and intact (right column; $b, d, f$ ) hemispheres taken from the same coronal sections. Brain regions shown are the primary somatosensory cortex $(a, b)$, retrosplenial cortex $(c$, $d)$, and postsubiculum $(e, f)$. The superficial layers are toward the right, left, and bottom of the photomicrographs for the somatosensory cortex, retrosplenial cortex, and postsubiculum, respectively. The figures to the left of the photomicrographs show the regions sampled, and the numbers indicate the distance (in millimeters) of the sections from bregma (Swanson, 1992). Scale bar, $500 \mu \mathrm{m}$.
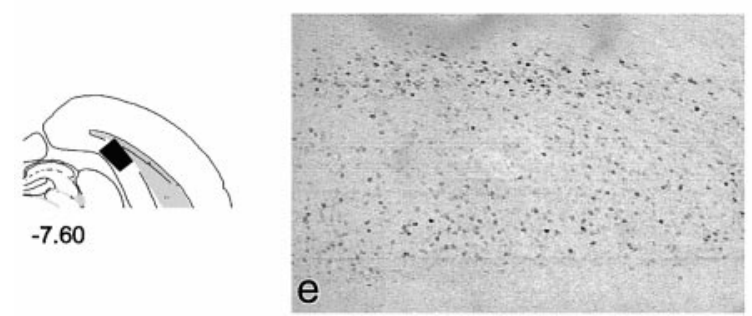

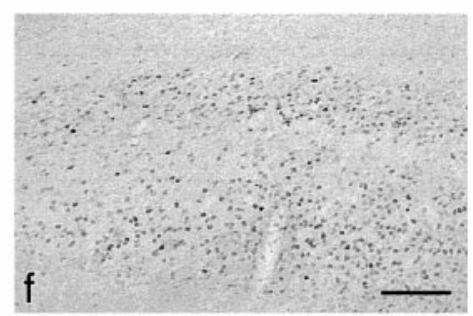

internal capsule (van Groen and Wyss, 1990b,c). The presubiculum, parasubiculum, and postsubiculum also project via the fornix to the laterodorsal thalamic nucleus (van Groen and Wyss, 1990b,c), but a substantial proportion of these inputs use the internal capsule route (Meibach and Siegel, 1977b). The greater importance of this second pathway and the fact that there was no difference in this structure in normal animals performing this task (Vann et al., 2000a) may explain the lack of a Fos difference in the laterodorsal nucleus. Although nucleus reuniens receives fornical inputs there was no significant hemispheric difference. Nucleus reuniens is, however, a midline nucleus with a large number of crossed projections (Wouterlood et al., 1990) that might lessen the difference seen across the two hemispheres. Thus, this null result should be treated cautiously.

The lateral septum receives dense hippocampal inputs via the fornix (Meibach and Siegel, 1977a; Swanson and Cowan, 1977; van Groen and Wyss, 1990a,b,c), and consistent with the hippocampal hypoactivity, the lateral septum had lowered Fos levels. In contrast, the medial septum, which has substantial fornical efferents but no direct fornical afferents (Swanson and Cowan, 1979), showed no interhemispheric Fos difference. This suggests that fornical inputs, rather than outputs, are critical in determining the effect of a fornix lesion on c-fos expression in the septal nuclei.

A number of regions showed indirect changes as they have few, if any, direct fornical inputs. Examples include the postrhinal cortex, which is innervated by the hippocampus, and the retrosplenial cortex, which is innervated by both the hippocampus and the anterior thalamic nuclei (Wyss and van Groen, 1992; Shibata, 1993). The significant reduction in postrhinal cortex contrasted with the perirhinal cortex, which also receives hippocampal inputs yet was unaffected by the fornix lesion. This finding not only provides further evidence for an involvement of the postrhinal cortex in spatial memory processes (Burwell and Amaral, 1998; Vann et al., 2000b), but also underlines the different role of the perirhinal cortex (Zhu et al., 1995, 1996; Wan et al., 1999).

The converse result, that is fornical inputs but no hemispheric change in Fos, was found in nucleus accumbens. Whereas this area receives fornical inputs from the dorsal (Brog et al., 1993) and ventral subiculum (Meibach and Siegel, 1977a; Canteras and Swanson, 1992), manipulations of nucleus accumbens typically have little effect on radial arm maze task performance (Schacter et al., 1989; Floresco et al., 1996). Furthermore, in normal animals there is no 
increase in accumbens Fos when performing the same task (Vann et al., 2000a). These results highlight the task-specific nature of the activity-related changes in nucleus accumbens (Bontempi and Sharp, 1997).

Two overall patterns emerge from this study. First, those sites known to impair radial arm maze performance or related tests of spatial memory when lesioned bilaterally, consistently showed abnormal Fos levels after unilateral fornix lesions. This applies to the hippocampus, entorhinal cortex, subiculum, retrosplenial cortex, and anterior thalamic nuclei (Walker and Olton, 1979; Morris et al., 1982; Olton, 1982; Sutherland et al., 1988; Taube et al., 1992; Sutherland and Hoesing, 1993; Aggleton et al., 1996; Byatt and Dalrymple-Alford, 1996; Kesner and Giles, 1998; Laxmi et al., 1999). Whereas there are conflicting reports on the importance of the medial prefrontal cortex for such tasks (Brito et al., 1982; Olton, 1982; Ragozzino et al., 1998; Delatour and Gisquet-Verrier, 2000), lesion data do indicate a modulatory role for the prelimbic area (Ragozzino et al., 1999; Delatour and Gisquet-Verrier, 2000), and this region showed changed Fos levels in the present study. Similarly, changes in supramammillary nucleus activity can disrupt spatial memory tasks (Pan and McNaughton, 1997), and again Fos changes were observed. A possible exception is the medial septum, but this may reflect the fact that it is functionally upstream from the fornix disconnection (Leranth et al., 1992; Kirk, 1998) and, hence, less sensitive to this manipulation.

A second pattern reflects the considerable overlap between those regions with a difference in Fos levels between the lesioned and intact hemisphere, and those that show increased Fos levels in normal animals performing the same radial arm maze task (Vann et al., 2000a,b). Of 39 sites examined in both studies, 10 sites were unresponsive to both manipulations, whereas 22 showed Fos level changes in both studies. In all cases except one (prelimbic cortex), an area that normally showed an increase in Fos after a spatial memory task, showed a decrease in the same task after fornix lesion. The few exceptions to this pattern included nucleus reuniens and parts of the subiculum, where crossed fornical projections may have affected the results. This association not only shows how fornix lesions selectively disrupt the same regions that are activated by task performance (Vann et al., 2000a,b), but also underlines how the effects of fornix transection extend well beyond the hippocampal formation. The discovery that fornix damage produces widespread changes in a system of structures thought to support a specific form of memory, allocentric spatial memory, shows how tract lesions can have effects that are both task- and site-specific, yet capable of affecting multiple regions. Such effects need to be taken into consideration when trying to understand why fornix damage in humans can result in anterograde amnesia (Heilman and Sypert, 1977; Gaffan and Gaffan, 1991; Hodges and Carpenter, 1991; D'Esposito et al., 1995; McMackin et al., 1995; Aggleton et al., 2000).

\section{REFERENCES}

Aggleton JP, Keith AB, Rawlins JNP, Hunt PR, Saghal A (1992) Removal of the hippocampus and transection of the fornix produce comparable deficits on delayed non-matching to position by rats. Behav Brain Res 52:61-71.

Aggleton JP, Hunt PR, Nagle S, Neave S (1996) The effects of selective lesions within the anterior thalamic nuclei on spatial memory in the rat. Behav Brain Res 81:189-198.

Aggleton JP, McMackin D, Carpenter K, Hornak J, Kapur N, Halpin S, Wiles CM, Kamel H, Brennan P, Carton S, Gaffan D (2000) Differential cognitive effects of colloid cysts in the third ventricle that spare or compromise the fornix. Brain 123:800-815.

Amaral DG, Kurz J (1985) An analysis of the origins of the cholinergic and noncholinergic septal projections to the hippocampal formation in the rat. J Comp Neurol 240:37-59.

Amaral DG, Witter MP (1995) Hippocampal formation. In: The rat nervous system (Paxinos G, ed), pp 443-493. San Diego: Academic.

Bontempi B, Sharp FR (1997) Systemic morphine-induced Fos protein in the rat striatum and nucleus accumbens is regulated by mu opioid receptors in the substantia nigra and the ventral tegmental area. J Neurosci 17:8596-8612.

Brito GNO, Thomas GJ, Davis BJ, Gingold SI (1982) Prelimbic cortex, mediodorsal thalamus, septum and delayed alternation in rats. Exp Brain Res 46:52-58.
Brog JS, Salyapongse A, Deutch AY, Zahm DS (1993) The patterns of afferent innervation of the core and shell in the "accumbens" part of the rat ventral striatum: immunohistochemical detection of retrogradely transported Fluoro-Gold. J Comp Neurol 338:255-278.

Burwell RD, Amaral DG (1998) Cortical afferents of the perirhinal, postrhinal, and entorhinal cortices of the rat. J Comp Neurol 398:179-205.

Burwell RD, Witter MP, Amaral DG (1995) Perirhinal and postrhinal cortices of the rat: a review of the neuroanatomical literature and comparison with findings from the monkey brain. Hippocampus 5:390-408.

Byatt G, Dalrymple-Alford JC (1996) Both anteromedial and anteroventral thalamic lesions impair radial-maze learning in rats. Behav Neurosci 110:1335-1348.

Canteras NS, Swanson LW (1992) Projections of the ventral subiculum to the amygdala, septum, and hypothalamus: a PHAL anterograde tracttracing study in the rat. J Comp Neurol 324:180-194.

Cassel JC, Duconseille E, Jeltsch H, Will B (1997) The fimbria-fornix/ cingular bundle pathways: a review of neurochemical and behavioural approaches using lesions and transplantation techniques. Prog Neurobiol 51:663-716.

Cassel JC, Cassel S, Galani R, Kelche C, Will B, Jarrard L (1998) Fimbriafornix vs selective hippocampal lesions in rats: effects on locomotor activity and spatial learning and memory. Neurobiol Learn Mem 69:22-45.

Curran T (1988) The fos oncogene. In: The oncogene handbook (Reddy EP, Skalka AM, eds), pp 307-325. Amsterdam: Elsevier.

Daitz HM, Powell TPS (1954) Studies of the connexions of the fornix system. J Neurol Neurosurg Psychiatry 17:75-82.

D'Esposito M, Verfaellie M, Alexander MP, Katz DI (1995) Amnesia following traumatic bilateral fornix transection. Neurology 45:1546-1550.

Delatour B, Gisquet-Verrier P (2000) Functional role of rat prelimbicinfralimbic cortices in spatial memory: evidence for their involvement in attention and behavioural flexibility. Behav Brain Res 109:113-128.

Dragunow M, Faull R (1989) The use of c-fos as a metabolic marker in neuronal pathway tracing. J Neurosci Methods 29:261-265.

Ennaceur A, Neave N, Aggleton JP (1992) Neurotoxic lesions of the perirhinal cortex do not mimic the behavioural effects of fornix transection in the rat. Behav Brain Res 80:9-25.

Floresco SB, Seamans JK, Phillips AG (1996) Differential effects of lidocaine inf usions into the ventral CA1/subiculum or the nucleus accumbens on the acquisition and retention of spatial information. Behav Brain Res $81: 163-171$

Gaffan D, Gaffan EA (1991) Amnesia in man following transection of the fornix. Brain 114:2611-2618.

Gage FH, Wictorin K, Fischer W, Williams LR, Varon S, Bjorklund A (1986) Retrograde cell changes in medial septum and diagonal band following fimbria-fornix transection: quantitative temporal analysis. Neuroscience 19:241-255.

Heilman KM, Sypert GW (1977) Korsakoff's syndrome resulting from bilateral fornix lesions. Neurology 27:490-493.

Herdegen T, Leah JD (1998) Inducible and constitutive transcription factors in the mammalian nervous system: control of gene expression by jun, fos, and krox, and CREB/ATF proteins. Brain Res Rev 28:370-490.

Herrera DG, Robertson HA (1996) Activation of c-fos in the brain. Prog Neurobiol 50:83-107.

Hodges JR, Carpenter K (1991) Anterograde amnesia with fornix damage following removal of IIIrd ventricle colloid cyst. J Neurol Neurosurg Psychiatry 54:633-638.

Hughes P, Lawlor P, Dragunow M (1992) Basal expression of Fos, Fosrelated, Jun, and Krox 24 proteins in the rat hippocampus. Brain Res Mol Brain Res 13:355-357.

Jay TM, Glowinski J, Thierry AM (1989) Selectivity of the hippocampal projection to the prelimbic area of the prefrontal cortex in the rat. Brain Res 505:337-340.

Jay TM, Burette F, Laroche S (1996) Plasticity of the hippocampalprefrontal cortex synapses. J Physiol (Paris) 90:361-366.

Kesner RP, Giles R (1998) Neural circuit analysis of spatial working memory: role of pre- and parasubiculum, medial and lateral entorhinal cortex. Hippocampus 8:416-423.

Kirk IJ (1998) Frequency modulation of hippocampal theta by the supramammillary nucleus, and other hypothalamo-hippocampal interactions: mechanisms and functional implications. Neurosci Biobehav Rev 22:291302.

Laxmi TR, Bindu PN, Raju TR, Meti BL (1999) Spatial memory impairment in ventral subicular lesioned rats. Brain Res 816:245-248.

Leranth C, Deller T, Busaki G (1992) Intraseptal connections redefined: lack of lateral septum to medial septum path. Brain Res 583:1-11.

McMackin D, Cockburn J, Anslow P, Gaffan D (1995) Correlation of fornix damage with memory impairment in six cases of colloid cyst removal. Acta Neurochir (Wien) 135:12-18.

Meibach RC, Siegel A (1977a) Efferent connections of the hippocampal formation in the rat. Brain Res 124:197-224.

Meibach RC, Siegel A (1977b) Thalamic projections of the hippocampal formation: evidence for an alternative pathway involving the internal capsule. Brain Res 134:1-12.

Morgan JI, Curran T (1991) Stimulus-transcription coupling in the nervous system: involvement of the inducible proto-oncogenes fos and jun. Annu Rev Neurosci 14:421-451. 
Morris RGM, Garrud P, Rawlins JNP, O'Keefe J (1982) Place navigation impaired in rats with hippocampal lesions. Nature (Lond) 297:681-683.

Moser M-B, Moser EI, Forrest E, Andersen P, Morris RGM (1995) Spatial learning with a minislab in the dorsal hippocampus. Proc Natl Acad Sci USA 92:9697-9701.

Naber PA, Caballero-Bleda M, Jorritsma-Byham B, Witter MP (1997) Parallel input to the hippocampal memory system through peri- and postrhinal cortices. NeuroReport 8:2617-2621.

Neave N, Nagle S, Aggleton JP (1997) Evidence for the involvement of the mammillary bodies and cingulum bundle in allocentric spatial processing by rats. Eur J Neurosci 9:941-955.

Olton DS (1982) Spatially organized behaviors of animals: behavioral and neurological studies. In: Spatial abilities: development and physiological foundations (Potegal M, ed), pp 335-360. New York: Academic.

Olton DS, Walker JA, Gage FH (1978) Hippocampal connections and spatial discrimination. Brain Res 139:295-308.

Olton DS, Becker JT, Handelmann GE (1979) Hippocampus, space, and memory. Behav Brain Sci 2:313-365.

Pan W-X, McNaughton N (1997) The medial supramammillary nucleus, spatial learning and the frequency of hippocampal theta activity. Brain Res 764:101-108.

Paxinos G, Watson C (1997) The rat brain in stereotaxic coordinates. New York: Academic.

Ragozzino ME, Adams S, Kesner RP (1998) Differential involvement of the anterior cingulate and prelimbic/infralimbic areas of the rat prefrontal cortex in spatial working memory. Behav Neurosci 112:1-11.

Ragozzino ME, Wilcox C, Raso M, Kesner RP (1999) Involvement of rodent prefrontal cortex subregions in strategy switching. Behav Neurosci 113:32-41.

Sagar SM, Sharp FR, Curran T (1988) Expression of c-fos protein in brain: metabolic mapping at cellular level. Science 240:1328-1331.

Schacter GB, Yang CR, Innis NK, Mogenson GJ (1989) The role of the hippocampal-nucleus accumbens pathway in radial-arm maze performance. Brain Res 494:339-349.

Shibata H (1993) Efferent projections from the anterior thalamic nuclei to the cingulate cortex in the rat. J Comp Neurol 330:533-542.

Steward O (1976) Topographic organization of the projections from the entorhinal area to the hippocampal formation of the rat. J Comp Neurol 167:285-314.

Sutherland RJ, Hoesing JM (1993) Posterior cingulate cortex and spatial memory: a microlimnology analysis. In: Neurobiology of cingulate cortex and limbic thalamus: a comprehensive treatise (Vogt BA, Gabriel M, eds), pp 461-477. Boston: Birkhauser.

Sutherland RJ, Rodriguez AJ (1989) The role of the fornix/fimbria and some related subcortical structures in place learning and memory. Behav Brain Res 32:265-277.

Sutherland RJ, Wishaw IQ, Kolb B (1988) Contributions of cingulate cortex to two forms of spatial learning and memory. J Neurosci 8:1863-1872.

Swanson LW (1981) A direct projection from Ammon's horn to prefrontal cortex in the rat. Brain Res 217:150-154.

Swanson LW (1992) Brain maps: structure of the rat brain. Amsterdam: Elsevier Science.

Swanson LW, Cowan WM (1977) An autoradiographic study of the organization of the efferent connections of the hippocampal formation in the rat. J Comp Neurol 172:49-84.

Swanson LW, Cowan WM (1979) The connections of the septal regions in the rat. J Comp Neurol 186:621-656.
Taube JS, Kesslack JP, Cotman CW (1992) Lesions of the rat postsubiculum impair performance on spatial tasks. Behav Neural Biol 57:131-143. Taubenfeld SM, Wiig KJ, Bear MF, Alberini CM (1999) A molecular correlate of memory and amnesia in the hippocampus. Nat Neurosci 2:309-310.

Tischmeyer W, Grimm R (1999) Activation of immediate early genes and memory formation. Cell Mol Life Sci 55:564-574.

van Groen T, Wyss JM (1990a) Extrinsic projections from area $\mathrm{CA}_{1}$ of the rat hippocampus: olfactory, cortical, subcortical, and bilateral hippocampal formation projections. J Comp Neurol 302:515-528.

van Groen T, Wyss JM (1990b) The connections of the presubiculum and parasubiculum in the rat. Brain Res 518:227-243.

van Groen T, Wyss JM (1990c) The postsubicular cortex in the rat: characterization of the fourth region of the subicular cortex and its connections. Brain Res 529:165-177.

Vann SD, Brown MW, Aggleton JP (2000a) Fos expression in the rostral thalamic nuclei and associated cortical regions in response to different spatial memory tests. Neuroscience, in press.

Vann SD, Brown MW, Erichsen JT, Aggleton JP (2000b) Fos imaging reveals differential patterns of hippocampal and parahippocampal subfield activation in rats in response to different spatial memory tasks. J Neurosci 20:2711-2718.

Walker JA, Olton DS (1979) Spatial memory deficit following fimbriafornix lesions: independent of time for stimulus processing. Physiol Behav 23:11-15.

Wan H, Aggleton JP, Brown MW (1999) Different contributions of the hippocampus and perirhinal cortex to recognition memory. J Neurosci 19:1142-1148.

Warburton EC, Aggleton JP, Muir JL (1998) Comparing the effects of selective cingulate cortex lesions and cingulum bundle lesions on water maze performance by rats. Eur J Neurosci 10:622-634.

Whishaw IQ, Jarrard LE (1995) Similarities vs differences in place learning and circadian activity in rats after fimbria-fornix section or ibotenate removal of hippocampal cells. Hippocampus 5:595-604.

Winer BJ (1971) Statistical principles in experimental design. New York: McGraw-Hill.

Witter MP, Groenewegen HJ, Lopes da Silva FH, Lohman AHM (1989) Functional organization of the extrinsic and intrinsic circuitry of the parahippocampal region. Prog Neurobiol 33:161-253.

Wouterlood FG, Saldana E, Witter MP (1990) Projection from the nucleus reuniens thalami to the hippocampal region: light and electron microscope tracing study in the rat with the anterograde tracer Phaseolus vulgaris-Leucoagglutin. J Comp Neurol 296:179-203.

Wyss JM, Swanson LW, Cowan WM (1980) The organization of the fimbria, dorsal fornix and ventral hippocampal commissure in the rat. Anat Embryol 158:303-316.

Wyss JM, van Groen T (1992) Connections between the retrosplenial cortex and the hippocampal formation in the rat: a review. Hippocampus $2: 1-12$.

Zhu XO, Brown MW, McCabe BJ, Aggleton JP (1995) Effects of novelty or familiarity of visual stimuli on the expression of the immediate early gene c-fos in rat brain. Neuroscience 69:821-829.

Zhu XO, McCabe BJ, Aggleton JP, Brown MW (1996) Mapping visual recognition memory through expression of the immediate early gene c-fos. NeuroReport 7:1871-1875. 